of the placenta left adherent; I am therefore inclined to attribute it to the absence of due contraction of the organ, after the placenta was removed. In regard to the cause of the phlebitis, it is a question whether it arose from the removal of the placenta, from loss of blood, or from some peculiar condition of the atmosphere. It is most probable that all had some influence in producing the result, as the act of removing the placenta, although it does not ordinarily induce phlebitis, yet necessarily acts as a predisposing, if not, occasionally, an exciting canse. As to the influence of the loss of blood, it is well known to surgeons that a large loss of blood predisposes any patient who has been operated upon, to an attack of phlebitis: this is emphatically pointed out by Sir $\cdot \mathbf{B}$. Brodie, in his lectures on pathology and surgery. The influence exerted by the atmosphere on the disease has been long recognised, and we usually find erysipelas and phlebitis to prevail at the same time.

The peculiar course which the disease pursued, is, I believe, quite unique, as it apparently commenced in the uterine veins, and extended to the inferior mesenteric through the anastamoses which occur between its small branches and those of the internal iliac. This, however, is a mere conjecture, as I was not allowed time to trace this out.

The diagnosis of the disease was readily made out, as the symptoms were so characteristic. Thus the shivering pain of the pubic region, fever, \&c., were indicative of phlebitis of the uterine sinuses, whilst the irregular ague fits, the peculiar diarrhcea, the pain of the right hypochondrium, and the subsequent ascites formed so remarkable a combination of symptoms, that they necessarily led to the belief that the disease consisted in inflammation of the trunk of the portal vein. The presence of ascites, and the peculiar diarrhea may be considered as the diagnostic marks by which phlebitis of the trunk of the porta may be distinguished from hepatic abscess, as irregular attacks resembling ague may, and frequently do arise during the progress of the latter disease. Jaundice, which is usually one of the prominent symptoms, was absent in this case, probably in consequence of the speedy death of the patient. The auscultatory signs of inflammation of the lung are frequently absent, even when the lung is studded with abscesses - in consequence of the morbid process being confined to the immediate vicinity of the purulent deposit.

Commercial-road East, 1848.

$=$

ON THE

\section{UTILITY OF ALKALIES IN THE TREATMENT OF RHEUMATISM.}

Bx J. I. FURNIVALL, M.D., Holloway.

Some remarks on the treatment of rheumatism by alkalies are published in Tue LANCET of 25 th November last. I have now, for nearly twenty years, been in the habit of treating rheumatism by means of alkalies, (the liquor potasse, the carbonate, bicarbonate of potass or sodæ; ) and as cases have multiplied in my practice during that long period, I have become more and more satisfied of their efficacy in preventing the supervention of heart disease; while as to their value in curing rheumatism, I beg to refer to reports published about a year ago, by Dr. Wright, of Birmingham.

$I$ have seldom used them alone in severe and threatening cases, though Dr. Wright has done so with great success; but considering that the inflammation and pyrexia were the effects or concomitants of the peculiar state of the blood in rheumatic fever, to remove which state alkalies are recommended, I have combined with the alkalies various other remedies-colchicum, to remove pain and lower excitement, mercury sometimes, \&c.

The results of my clinical observations have been these,-

First. That no case of supervening heart disease has ever occurred in my practice since $I$ have administered alkalies in rheumatic cases; nor will they, in my opinion, if the concomitant inflammation and fever have at the same time been properly attended to.

Secondly. That many cases of rheumatic fever are on record which have been energetically treated by medical men of eminence, but without the use of alkalies, in which heart disease has ensued, and proved fatal.

Thirdly. That mercury and colchicum, separate or combined, and either or both pushed to their utmost extent, will not secure the patient from heart disease, without the addition of alkalies.

Permit me to refer to some observations which are published in The Lancer of June 1st, 1844, page 304, and June 29th, 1844 , page 450 , and of March 31st, 1846 , page 328 , et sequent.

Now, seeing that heart disease is a dreadful affliction, (in the poor man overpoweringly so;) seeing that its supervention is not merely confined to acute cases of rheumatic fever, and that it may arise in all cases of rheumatism, even in those seemingly slight forms of chronic pains; and seeing that alkalies may easily be combined with other remedies in the treat ment of rheumatism, I would again press on my medical brethren the necessity of prescribing alkalies in all cases of rheumatism.

Holloway, Dec. 1848.

\section{REMARKS ON}

\section{THE CONTAGION OF SECONDARY SYPHILIS.}

Bx GEORGE GARSON, Esq., Surgeon, Stromness.

Is March, 1846, I was consulted by a married man for ulceration on the glans penis. He admitted having had interoourse with a strange female about two months previously, and thereafter experienced a smarting sensation about the glans, which was followed by the present sore. There was also a scaly eruption on the scalp; the throat vascular, and swollen.

In June he had two small tumours, each of about the size of a bean, near the anus, which gave him much pain, on account of the discharge and excoriation. He had felt an uneasiness about the anus for some time, which he thought proceeded from piles. The mucous membrane of the mouth was white and flabby.

His wife has suffered some time from heat and swelling about the genitals. When visited in the end of June, she was unable to walk erect, and had swelling and increased temperature of the vulva, with extensive superficial ulceration of the right labia, and great vascularity about the anus; the vagina also very vascular.

May, 1847.-Visited the family, when two children wexe shown me, having extensive redness, with discharge from the anus; and another, aged nine years, who had been in bad health, accompanied with falling of the hair, which was then very thin, and she had sore throat, as also condylomatous swellings about the anus.

In this same month, I was called on by another member of the same family, aged fourteen, then out in service, but who had lived with his parents during the preceding harvest and winter, and slept in the same bed with his little sister, aged nine years. It was after his residence at home that he first felt uneasiness about the fundament, to which a discharge succeeded. The anus was surrounded by a considerable number of flat swellings, more elevated, and with narrower base, near its verge. He walked very awkwardly, on account of the irritation. Had swellings on each side of his neck, which spontaneously disappeared; also sore-throat, chiefly in the morning; tonsils enlarged, and had the appearance of numerous small, ulcerated points; pharynx covered with a dirtygreyish mucus.

The greater number of these cases were tedious, partly on account of being seldom seen, and partly on account of the poverty and filth of the persons themselves. They were all treated by mercury.

Remarks. -I have thought it a duty to publish these cases, as they appear to me to be of some value in settling the question as to the communicability of secondary syphilis by contact, though not in accordance with the views advocated by Hunter, Ricord, and Acton. There is no doubt on my mind that the father of this family was the source whence all the others received infection; and in none, except his wife, could anything like primary ulceration be traced. Let it be remembered that they lived in a rural district, and that not only the girl of nine, and the boy of fourteen, exhibited the disease, but also two younger children. The combination of symptoms under which the two elder children laboured, in my estimation, show clearly the nature of the disease. stromness, May, 1848.

\section{ZRebítios.}

Outlines of Lectures on the Nature, Causes, and Treatment of Insanity. By Sir A. Morison, M.D. \&c. Edited by his Son, T. C. Morison, Esq. Fourth Edition, with Plates. London: Longman and Co.; Highley. 1848. pp. 481.

THE absence of any instruction in the nature and treatment of mental disease in the usual course of medical education, 